\title{
The function of Drosophila p53 isoforms in apoptosis
}

\author{
B Zhang ${ }^{1,2}$, M Rotelli ${ }^{1}$, M Dixon ${ }^{1}$ and BR Calvi ${ }^{\star *}$
}

The p53 protein is a major mediator of the cellular response to genotoxic stress and is a crucial suppressor of tumor formation. In a variety of organisms, p53 and its paralogs, p63 and p73, each encode multiple protein isoforms through alternative splicing, promoters, and translation start sites. The function of these isoforms in development and disease are still being defined. Here, we evaluate the apoptotic potential of multiple isoforms of the single p53 gene in the genetic model Drosophila melanogaster. Most previous studies have focused on the p53A isoform, but it has been recently shown that a larger p53B isoform can induce apoptosis when overexpressed. It has remained unclear, however, whether one or both isoforms are required for the apoptotic response to genotoxic stress. We show that $\mathrm{p} 53 \mathrm{~B}$ is a much more potent inducer of apoptosis than $\mathrm{p} 53 \mathrm{~A}$ when overexpressed. Overexpression of two newly identified short isoforms perturbed development and inhibited the apoptotic response to ionizing radiation. Analysis of physiological protein expression indicated that p53A is the most abundant isoform, and that both p53A and p53B can form a complex and co-localize to sub-nuclear compartments. In contrast to the overexpression results, new isoformspecific loss-of-function mutants indicated that it is the shorter p53A isoform, not full-length $\mathrm{p} 53 \mathrm{~B}$, that is the primary mediator of pro-apoptotic gene transcription and apoptosis after ionizing radiation. Together, our data show that it is the shorter p53A isoform that mediates the apoptotic response to DNA damage, and further suggest that p53B and shorter isoforms have specialized functions.

Cell Death and Differentiation (2015) 22, 2058-2067; doi:10.1038/cdd.2015.40; published online 17 April 2015

The p53 transcription factor mediates the cellular response to a variety of stresses and is crucial for suppressing tumorigenesis. ${ }^{1}$ The genomes of humans and other vertebrates encode two other p53 family members, p63 and p73. ${ }^{2}$ Complicating the picture further, all three p53 family members encode a large number of protein isoforms, whose different activities in development and disease are still being defined. ${ }^{2}$ Here, we investigate the apoptotic function of multiple protein isoforms encoded by the single p53 family member in the genetic model organism Drosophila melanogaster.

Genotoxic and other stresses activate the p53 protein to induce multiple downstream responses, including DNA repair, cell cycle arrest, cell senescence, and apoptosis. ${ }^{3-5}$ The vertebrate paralogs p63 and p73 not only have unique developmental functions, but also have roles in stress response and tumor suppression that overlap that of $p 53 .^{6-9}$ All three paralogs primarily act as homotetrameric transcription factors, but also have transcription-independent functions. ${ }^{4,10-12}$ In recent years, the list of processes that p53 family members regulate has been growing and includes metabolism, autophagy, metastasis, stem cell division, and aging. ${ }^{2,13}$

A current challenge for understanding the function of p53 family members is that they all encode a large number of protein isoforms, a property that is conserved among vertebrates and some invertebrates. ${ }^{2,14}$ The human p53 gene encodes at least 12 different protein isoforms through the use of alternative promoters, splicing, and translation. ${ }^{15,16}$ Fulllength p53 protein contains an $\mathrm{N}$-terminal transcriptional trans-activation domain (TAD), a DNA binding domain (DBD), an oligomerization domain (OD), and a C-terminal domain (CTD). ${ }^{17}$ Shorter p53 isoforms that lack all or part of the $\mathrm{N}$-terminal TAD ( $\triangle \mathrm{N}$ isoforms) are expressed at elevated levels in certain cancers where they bind full-length p53 and directly interfere with its function as transcriptional activator. $^{18-21}$ Other p53 isoforms lack sites of covalent modification and protein-protein interaction that alter p53 activation by upstream signals and its downstream target gene specificity. ${ }^{15,22,23}$ Full-length p63 mediates developmental apoptosis of defective oocytes and prevents cancer metastasis, whereas shorter isoforms have essential developmental functions in the maintenance and proliferation of stem cells in several tissues. ${ }^{8,9,24-31}$ The $p 73$ gene encodes over 14 protein isoforms. $^{2}$ Full-length p73 regulates neuronal stem cell maintenance, metabolism, spermatogenesis, cell cycle arrest, and apoptosis, whereas recent evidence suggests that elevated expression of short p73 isoforms contributes to several types of cancer. ${ }^{32,33}$ The current data support that differential expression of p53, p63, and p73 isoforms in different developing tissues and tumors have important functional consequences, but the understanding of these complex interactions is far from complete.

Drosophila melanogaster has a single p53 family member, which is more similar to p53 than p63/73 in that it lacks the

\footnotetext{
${ }^{1}$ Department of Biology, Indiana University, Bloomington, IN, USA

*Corresponding author: BR Calvi, Department of Biology, Indiana University, 1001 East 3rd St., Jordan Hall, Bloomington, IN 47405, USA. Tel: +1 812855 5450; Fax: +1 812855 6705; E-mail: bcalvi@indiana.edu

${ }^{2}$ Current address: Advanced Cell Diagnostics, Inc, 3960 Point Eden Way, Hayward, CA 94545, USA

Abbreviations: TAD, trans-activation domain; DBD, DNA binding domain; OD, oligomerization domain; CTD, C-terminal domain; SAM, sterile alpha motif; IR, Ionizing radiation; hid, head involution defective; rpr, reaper; $\mathrm{Ch}$, mCherry; GFP, green fluorescent protein

Received 30.12.14; revised 02.3.15; accepted 03.3.15; Edited by E Baehrecke; published online 17.4.15
} 
C-terminal sterile alpha motif (SAM) that the p63/p73 paralogs contain. ${ }^{7,34-37}$ Since the initial description of Drosophila p53, most investigations into its function have focused on a single $44 \mathrm{kD}$ protein isoform, but expression of a $56 \mathrm{kD}$ isoform has also been described. ${ }^{15,34,35,38}$ The current genome annotation based on deep RNA sequencing predicts four mRNA isoforms $(A, B, C$, and $E)$ and three proteins, with transcript $A$ and $C$ encoding the same well-characterized $44 \mathrm{kD}$ protein $^{39,40}$ (Figure 1a). The well-studied p53A isoform is also known as $\triangle$ Np53 because it is 110 amino acid (AA) shorter in its $\mathrm{N}$-terminal TAD than the longest $56 \mathrm{kD}$ p53B isoform (Figure 1a). ${ }^{16,41}$ Previous evidence indicated that p53B can induce apoptosis when overexpressed, but the normal physiological function of $\mathrm{p} 53 \mathrm{~B}$ has not been evaluated. ${ }^{41,42}$ Two shorter isoforms have also been predicted by RNA-Seq. The p53E mRNA isoform appeared in the annotated genome in the year 2014 and predicts a 334 AA ( 38 kD) protein (Figures $1 \mathrm{a}$ and $\mathrm{b}$ ). Translation of $\mathrm{p53E}$ is predicted to start at the first ATG in its unique exon 8, resulting in a unique $10 \mathrm{AA}$ $\mathrm{N}$-terminus, while the rest of the protein is identical to p53A and $\mathrm{p} 53 \mathrm{~B}$ isoforms and includes the DNA binding and oligomerization domains. This new p53E prediction supplanted a previous RNA-Seq prediction called p53D that had an additional two nucleotides at the junction of its first and second exon (exons 8-9), which put translation from the first ATG out of frame with the other isoforms (Figure 1a). Translation of $\mathrm{p53D}$, therefore, was proposed to start at a downstream ATG in the common exon 9, in frame with the other isoforms and predicting a 318 AA ( 36 kD) protein (Figures 1a and b). Thus, it appears that the Drosophila p53 gene, like its human ortholog, encodes multiple isoforms, but their functions have not been fully defined. Here, we investigate the ability of these Drosophila p53 isoforms to regulate apoptosis.

\section{Results}

All p53 isoforms disrupt development when overexpressed. We sought to determine whether different p53 isoforms participate in apoptosis. Extant p53 loss-of function alleles cannot be used to address this question because they disrupt multiple isoforms (Figure 1a). ${ }^{43-45}$ We therefore began with an overexpression approach, using the GAL4/ UAS system to evaluate in parallel the ability of the $A, B, E$, and $D$ protein isoforms to induce apoptosis when overexpressed in a variety of tissues. To construct these transgenes, PCR products that spanned the start to stop codons in the cDNAs were tagged on the $\mathrm{N}$-terminus with six Myc epitope tags, fused to the UAS promoter, and inserted into flies at the same attP genomic docking site using phiC31 transformation.

We first expressed the p53 isoform transgenes ubiquitously from early in development using an Actin5C:GAL4 driver,

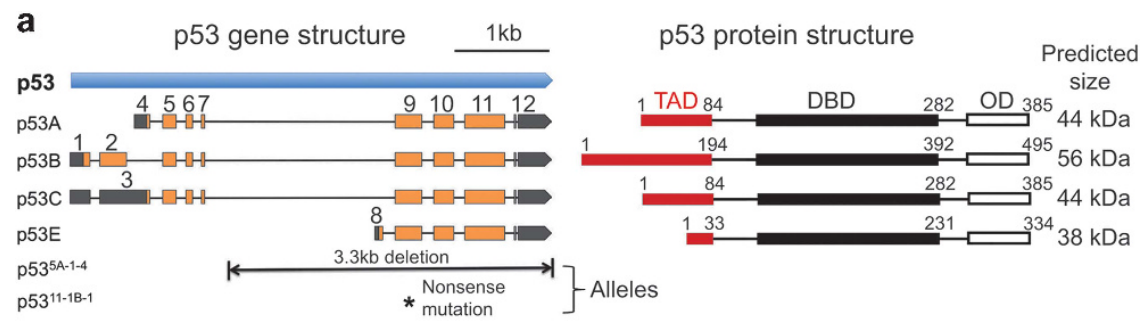

b

553D CAAGCTGGAACATGAAGCTCTATCAGCTCTATGAGCGCAAAGTCAATCCGTGCTGCGCGAAATGATGCTGCAG p53E CAAGCTGGAACATGAAGCTCTATCAGCTCTATGAGCGCAAA--CAATCCGTGCTGCGCGAAATGATGCTGCAG $\begin{array}{lllllllllllllllllllllllll}+1 & & M & \mathbf{K} & \mathbf{L} & \mathbf{Y} & \mathbf{Q} & \mathbf{L} & \mathbf{Y} & \mathbf{E} & \mathbf{R} & \mathbf{K} & \mathbf{Q} & \mathbf{S} & \mathbf{V} & \mathbf{L} & \mathbf{R} & \mathbf{E} & \mathbf{M} & \mathbf{M} & \mathbf{L} & \mathbf{Q}\end{array}$

Figure 1 Predicted p53 mRNA and protein isoforms. (a) The schematic of the current p53 gene annotation from Flybase predicts multiple RNA transcripts (left) and protein isoforms (right). Exons are boxes, with predicted ORFs in orange and $5^{\prime}$ or $3^{\prime}$ UTRs in black. Below are the molecular lesions in two extant null mutants that disrupt all isoforms. To right are shown predicted protein isoform sizes and structures of transcriptional transactivation domains (TAD), DNA binding domain (DBD), and oligomerization domain (OD) (b) Predicted 5' of mRNA and protein coding of p53D and p53E in exon 8 and part of exon 9. The two nucleotides that differ between the p53D and p53E exon junction are shown in red. Predicted ATG start codons and methionines for each isoform are shown in red. AAs in blue are present in p53E but not p53D. Alignment with the coding regions of the other isoforms begins with the glutamine $(Q)$ at the $5^{\prime}$ end of exon 9

Table 1 The effects of UAS:p53 isoform transgenes induced by different GAL4 drivers

\begin{tabular}{|c|c|c|c|c|}
\hline & \multicolumn{4}{|l|}{ GAL4 drivers } \\
\hline & Actin 5C:GAL4 & GMR:GAL4 & hsp70:GAL4 & Engrailed:GAL4 \\
\hline Expression pattern & $\begin{array}{l}\text { Ubiquitous from } \\
\text { embryogenesis }\end{array}$ & Photoreceptor cells & Ubiquitous after heat induction & Embryo, imaginal discs \\
\hline UAS:Myc:p53A & Lethal & $\begin{array}{l}\text { Apoptosis photoreceptors, } \\
\text { Rough eye }\end{array}$ & Apoptosis all stages & $\begin{array}{l}\text { Apoptosis in posterior } \\
\text { wing and other discs }\end{array}$ \\
\hline UAS:Myc:p53B & Lethal & $\begin{array}{l}\text { Strong apoptosis photoreceptors, } \\
\text { No eyes }\end{array}$ & Strong apoptosis all stages & Embryonic lethal \\
\hline UAS:Myc:p53D & Lethal & Mild rough eye & Repression apoptosis after IR & n.d. \\
\hline UAS:Myc:p53E & Lethal & Mild rough eye & Repression apoptosis after IR & n.d. \\
\hline
\end{tabular}


which resulted in $100 \%$ lethality before adulthood for each isoform, indicating that they are all biologically active (Table 1). To examine the effect on development further, we used GMR: GAL4 to induce expression posterior to the morphogenetic furrow of the larval eye disc and examined the morphology of adult eyes. ${ }^{46}$ GMR:GAL4 /+ was used as a negative control because it has been shown that this GAL4 driver alone can cause apoptosis and a rough eye phenotype dependent on gene dosage and temperature. However, at $21^{\circ} \mathrm{C}$, heterozygous GMR:GAL4 /+ adult flies had a normal adult eye morphology (Figure 2a). In contrast, GMR:GAL4 /+; UAS:6XMyc-p53A /+ flies had rough eyes with fused and irregular rows of ommatidia and bristles, consistent with previous reports for overexpressed p53A from $\mathrm{P}$ element transgenes (Figure 2b). ${ }^{35,47}$ Expression of UAS:6XMyc-p53B resulted in a much more severe phenotype, with a complete absence of eyes in all adults (Figure 2c). Expression of UAS:6XMyc-p53D and UAS:6XMyc-p53E also resulted in an adult rough eye phenotype, although UAS:6XMyc-p53D was slightly less severe than UAS:6XMyc-p53E (Figures $2 \mathrm{~d}$ and e) (Table 1).

To determine whether GMR:GAL4-driven expression of the p53 isoforms induced apoptosis, we labeled larval eye discs with antibodies against the cleaved Drosophila Caspase called Dcp-1. ${ }^{48}$ These animals also contained a UAS:GFP transgene that reported GMR:GAL4-driven expression in cells behind the morphogenetic furrow (Figure 2a'). Consistent with previous reports, the GMR:GAL4/+ alone control did have somewhat more cleaved Dcp-1 labeled cells than wild type, although the presence of apoptotic cells was variable among eye discs (Figure 2a'). Expression of p53A and p53B isoforms resulted in an increase in the number of Dcp-1-labeled cells behind the morphogenetic furrow, with p53B clearly inducing the most apoptotic cells (Figures 2a'-c'). p53B overexpression also resulted in the greatest fluorescent intensity of cleaved Dcp-1 labeling per cell, and these cells were closer behind the morphogenetic furrow, suggesting that p53B is the strongest and most rapid inducer of Caspase cleavage (Figure 2c'). The eye discs overexpressing p53D and p53E also had apoptotic cells behind the furrow, but it was unclear whether there was a significant increase relative to the variable level of apoptosis caused by GMR:GAL4 alone (Figures 2d' and e'). Similar results were obtained with GAL4-driven expression in other tissues, with p53B expression always resulting in the most apoptotic cells (Table 1$)^{42}$

Overexpression of p53A or p53B induces apoptosis in ovarian follicle cells. To quantify the apoptotic potential of p53 isoforms, we overexpressed them in the adult ovary using hsp70:GAL4, a GAL4 driver that does not induce cell

Figure 2 Overexpression of p53 isoforms perturbs eye development. (a-e) Adult eye morphology in control (GMR:GAL4 /+; UAS:GFP /+) (a) or GMR:GAL4 /+; UAS:GFP / UAS:Myc:p53 of the indicated isoform (b-e). (a'-e') Third instar eye discs from the same strains labeled with anti-cleaved Dcp-1 (Casp, red) and anti-GFP (green), which reports GMR:GAL4-driven expression behind the morphogenetic furrow. Flies were raised at $21{ }^{\circ} \mathrm{C}$. Posterior is to the right for all images. Scale bars are $30 \mu \mathrm{m}$ in a'-e'
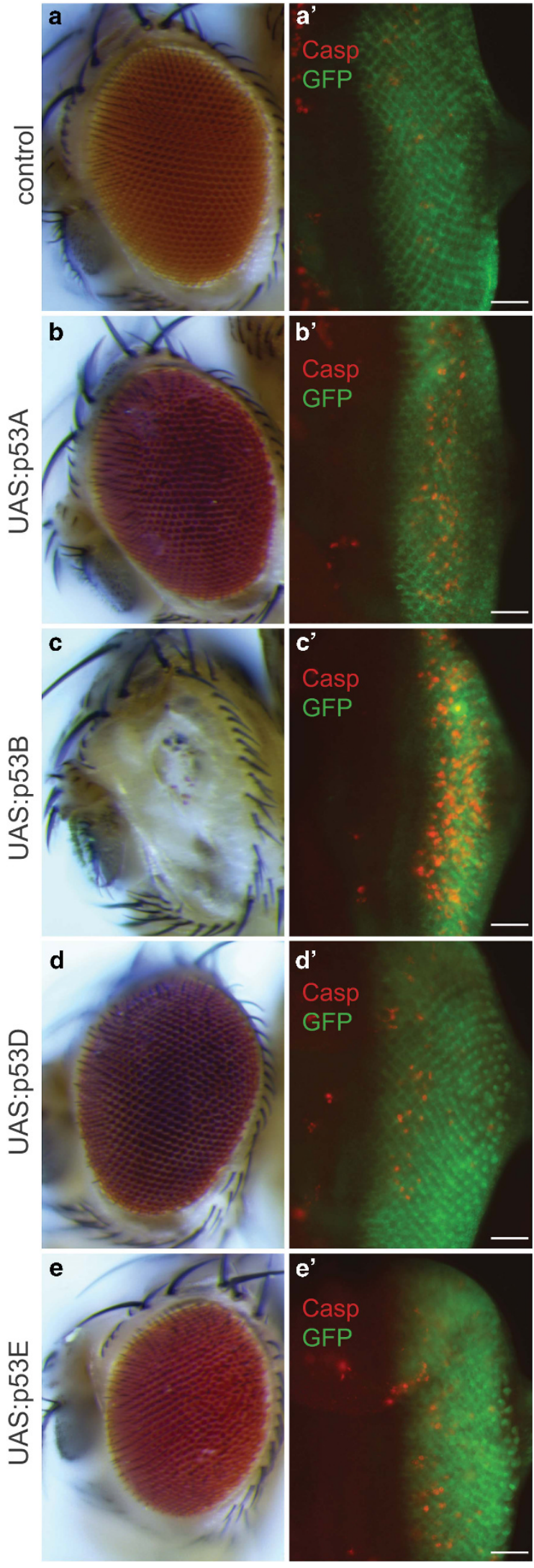
death on its own in the somatic follicle cells during stages 1-6 of oogenesis (Figures $3 a$ and $\mathrm{f}$ ). We induced expression with a 30-min heat pulse and measured apoptosis $6 \mathrm{~h}$ later by labeling for cleaved Dcp-1. Both wild-type and hsp70: GAL4 alone had a few DCP-1-positive polar follicle cells, which undergo developmental cell death before stage 6 (Figures $3 a$ and f). ${ }^{49}$ Expression of p53A or p53B isoforms resulted in a significant increase in the number of apoptotic cells, with overexpression of p53B again having the strongest effect, whereas p53D and p53E did not induce apoptosis significantly (Figures $3 b-f)$. Co-labeling for the Myc epitope tag indicated that all the isoforms were highly expressed and concentrated in a subnuclear compartment adjacent to the heterochromatic chromocenter (Figures $3 b-e)$. These results further suggest that the p53A and p53B isoforms can induce apoptosis when overexpressed, with the longest $\mathrm{p} 53 \mathrm{~B}$ isoform being the most potent.

Overexpression of p53B stimulates, and short isoforms inhibit, the apoptotic response to ionizing radiation. In vertebrates, shorter p53 isoforms can inhibit the apoptotic response to genotoxic stress. ${ }^{2,16}$ We therefore assessed whether the overexpression of p53 isoforms altered the apoptotic response of ovarian follicle cells to ionizing radiation (IR). Isoform expression was induced using hsp70:GAL4 at time zero, adult females were irradiated with 4000 rads of gamma rays $2 \mathrm{~h}$ later, and ovaries labeled for cleaved Dcp-1 at $6 \mathrm{~h}$ after p53 expression as before.
The number of apoptotic cells was greater in irradiated ovaries that expressed $\mathrm{p} 53 \mathrm{~A}$ or $\mathrm{p} 53 \mathrm{~B}$ versus irradiation alone, but only significant for p53B (Figures $4 a-c$, and f). In contrast, overexpression of the short isoforms p53D and p53E significantly reduced the number of apoptotic follicle cells after irradiation (Figures $4 a$ and $d-f$ ). These results suggest that overexpression of the potent p53B can increase apoptosis after irradiation, whereas the shorter isoforms inhibit the apoptotic response.

p53A is the most abundant protein isoform in larval imaginal disc and brain. We next evaluated the physiological expression and function of different isoforms. We first examined the protein expression levels of p53 protein isoforms by western blotting using an antibody raised against the human p53 C-terminus, which is conserved in all Drosophila isoforms. ${ }^{41,42}$ Western blotting of wild-type larval brain and imaginal disc (B-D) extracts revealed an $\sim 48 \mathrm{kDa}$ band, close to the predicted size of the $43.7 \mathrm{kDa}$ p53A protein isoform, that was not detected in extracts from $p 53^{5 A-1-4}$ null mutants, consistent with previous results from our lab and others (Figure $5 \mathrm{a}$, lanes 1, 2). ${ }^{16,41,42}$ The predicted p53B $(55.6 \mathrm{kDa})$ and $\mathrm{p53D} / \mathrm{E}(\sim 36-38 \mathrm{kDa})$ isoforms were not detected, although all lanes had a non-specific $72 \mathrm{kDa}$ band (Figure 5a).

To investigate $\mathrm{p} 53$ isoform expression further, we used BAC recombineering to tag p53 with fluorescent proteins (Figure 5b,Table 2). We previously described two fly strains transformed with a wild-type $\sim 24$ kb p53 genomic BAC clone
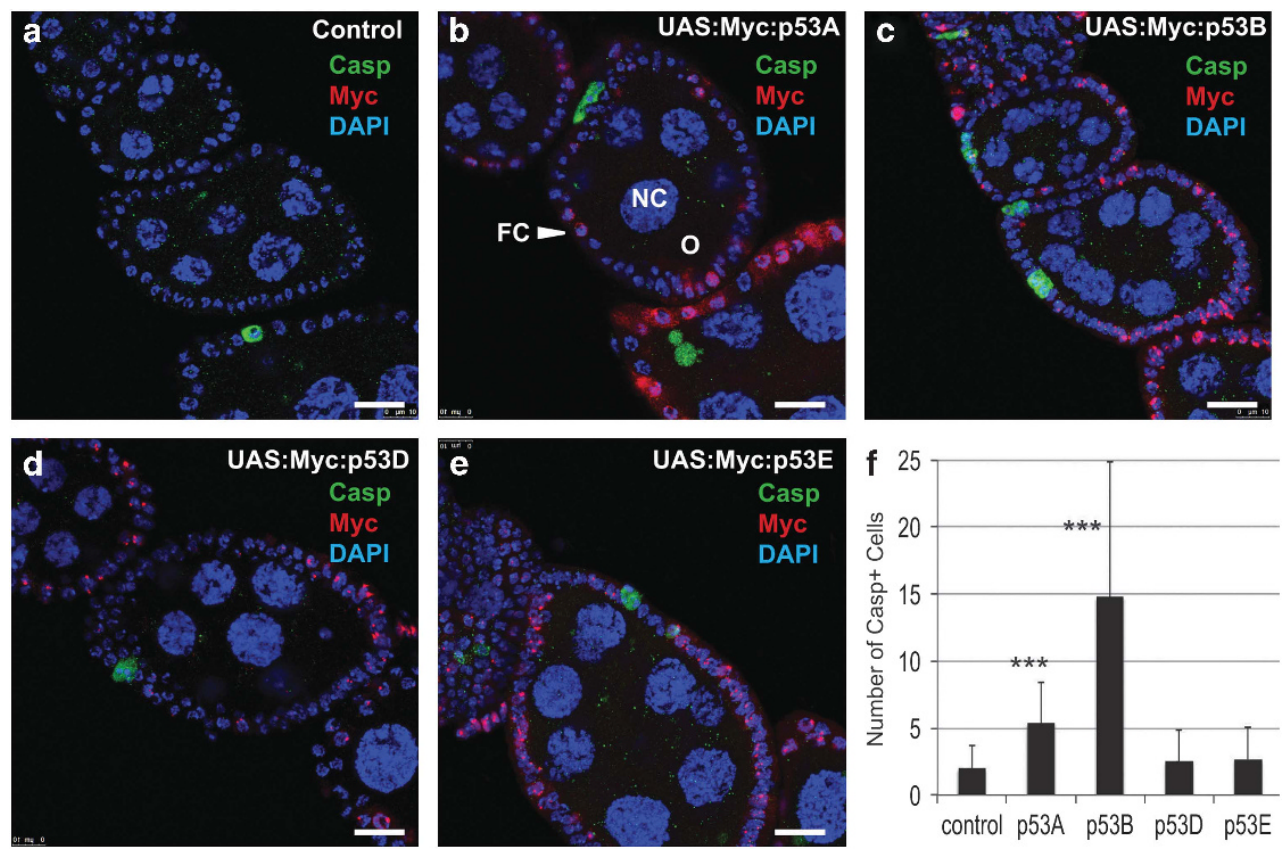

Figure 3 Overexpression of p53A or p53B induces apoptosis in ovarian follicle cells. (a-e) Anti-cleaved Dcp-1 (Casp, green), anti-Myc (red), and DAPI (blue) labeling in early stage egg chambers from adult females heterozyogous for hsp70:GAL4/+ alone (control, a) or with the indicated UAS:Myc:p53 isoform. (b-e) Ovaries were fixed and labeled $6 \mathrm{~h}$ after a 30-min heat pulse. Images are confocal sections through the middle of the egg chambers. In these strains, hsp70:GAL4 induces p53 isoform expression in the somatic follicle cells $(\mathrm{FC})$ on the surface of the egg chambers, but not the germline nurse cells (NC) or oocyte (O). Scale bars are $15 \mu \mathrm{m}$ (f) Quantification of the average number of apoptotic follicle cells labeled with cleaved Dcp-1 per ovariole between stages 1 and 6 of oogenesis. Mean and sample standard deviations are shown for pooled counts of $2-5$ biological replicates with 30 ovarioles per sample ${ }^{* \star *} P<0.0001$ relative to hsp70:GAL4 /+ control) 

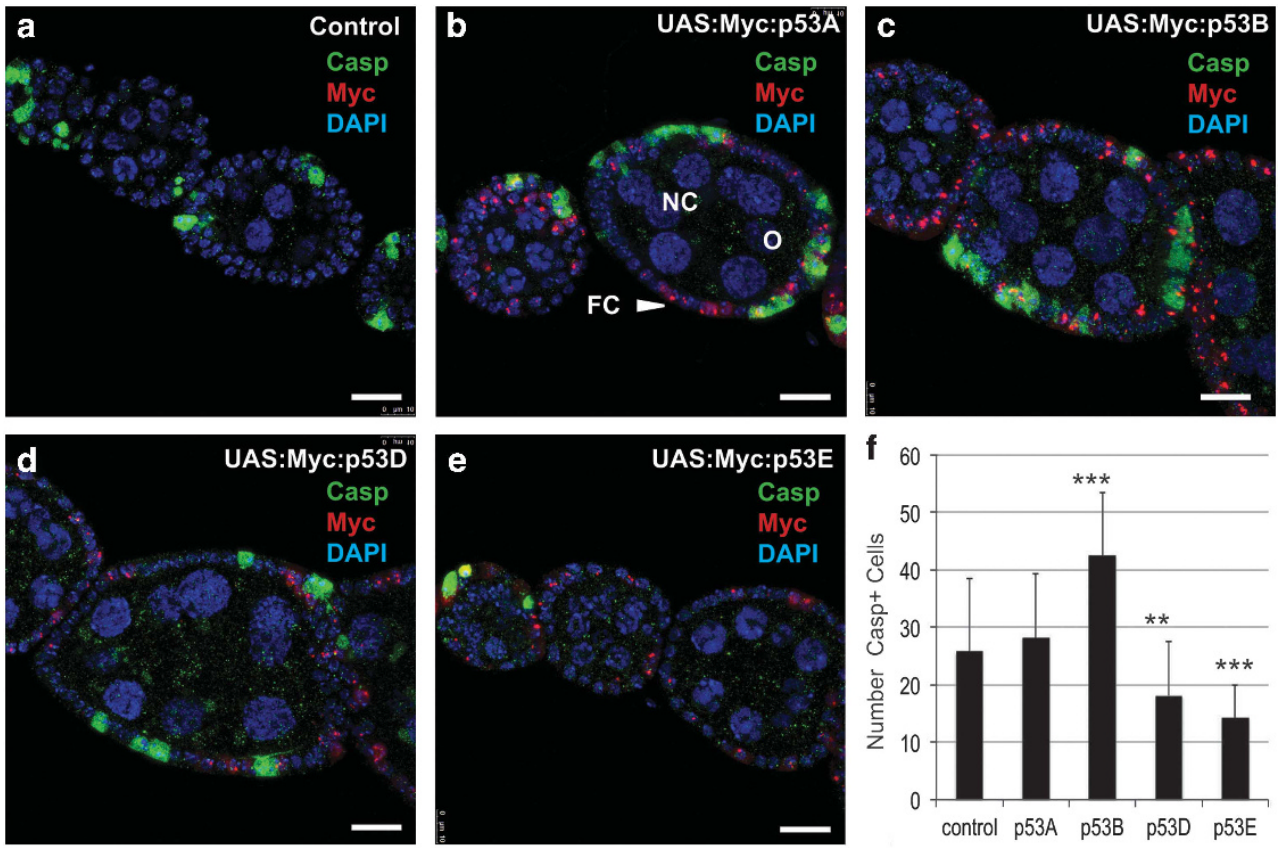

Figure 4 Overexpression of p53B stimulates, and short isoforms inhibit, the apoptotic response to IR. (a-e) Anti-cleaved Dcp-1 (Casp, green), anti-Myc (red), and DAPI (blue) labeling in early stage egg chambers from adult females heterozyogous for hsp70:GAL4/+ alone (control, a) or with the indicated UAS:Myc:p53 isoform after irradiation. (b-e) Ovaries were fixed and labeled $6 \mathrm{~h}$ after a 30-min heat pulse and $4 \mathrm{~h}$ after irradiation with 4000 rads of gamma rays. Images are confocal sections through the middle of the egg chambers. Follicle cells (FC), nurse cells (NC), and oocyte (O). Scale bars are $15 \mu \mathrm{m}$. (f) Quantification of the average number of apoptotic follicle cells labeled with cleaved Dcp-1 per ovariole between stages 1 and 6 of oogenesis. Mean and sample standard deviations of Dcp-1-positive cells with 30 ovarioles per sample ${ }^{* * *} P<0.0001,{ }^{* *} P=0.0002$ relative to hsp70:GAL4 /+ control)

and a derivative in which mCherry was fused to the common C-terminus of all the isoforms (p53-Ch). ${ }^{42,50}$ This BAC clone contains $\sim 17 \mathrm{~kb} 5^{\prime}$ and $\sim 3 \mathrm{~kb} 3^{\prime}$ of the 553 transcription unit and is expressed under control of the normal p53 regulatory regions, and both BACs were transformed into the same attP docking site using phiC 31 transformation. Our previous results indicated that both the wild-type and the p53-Ch BAC rescued the defective apoptotic response of $p 53^{5 A-1-4}$ and $p 53^{11-1 B-1}$ null alleles. ${ }^{42}$ Western blotting of extracts from the p53-Ch; $p 53^{5 A-1-4}$ strain with p53 antibodies revealed an abundant protein at $\sim 72 \mathrm{kDa}$, consistent with the predicted size of a p53A-mCherry fusion protein (Figure $5 \mathrm{a}$ ).

We next used BAC recombineering to tag the major p53A and p53B isoforms individually on their $\mathrm{N}$-termini. In two different BACs, p53A was tagged on its N-terminus with GFP, with or without triple stop codons in the p53A unique $5^{\prime}$ exon (GFP-p53A and GFP-p53ASTOP) (Figure 5b). In two other BACs, p53B was tagged on its $\mathrm{N}$-terminus with mCherry, with or without triple stop codons in the p53B unique $5^{\prime}$ exon (Chp53B and Ch-p53BSTOP) (Figure 5b). It is important to note that each of these BACs potentially expresses the other, untagged, wild-type isoforms (Table 2). Similar to the C-terminal fusions, anti-p53 western analysis of the GFP$p 53 A ; p 53^{5 A-1-4}$ strain revealed a single $\sim 72 \mathrm{kDa}$ band, which was absent from the GFP-p53ASTOP; $p 53^{5 A-1-4}$ strain, confirming that this band indeed represents the tagged p53A isoform (Figure $5 \mathrm{a}$, lane 4,5 ). Analysis of the Ch-p53B; $p 53^{5 A-1-4}$ strain revealed a faint $\sim 85 \mathrm{kDa}$ band, consistent with the predicted size of the mCherry-p53B fusion protein, which was not detected in the Ch-p53BSTOP; p53 $53^{5 A-1-4}$ extracts (Figure 5a, lanes 6-7). In both Ch-p53B; p53 5 5-1-4 and Ch-p53BSTOP; $p 53^{5 A-1-4}$, the p53 antibody detected a 48-kDa band that was similar in size and abundance to p53A in wild-type flies, confirming that these p53B-recombineered BACs express wild-type p53A (Figure 5a, lanes 2, 6, and 7). In summary, these results indicate that p53A is the most abundant protein isoform in larval brain and imaginal discs.

GFP-p53A and Ch-p53B localize to nuclear compartments. We used the GFP-p53A and Ch-p53B trangenes to determine whether these isoforms have similar cellular locations. Both GFP-p53A; $p 53^{5 A-1-4}$ and Ch-p53B; $p 53^{5 A-1-4}$ were concentrated into one to two distinct nuclear compartments (Figures 5c-d'). However, Ch-p53B expression was only detected in small patches of imaginal disc cells, suggesting that the overall low level of this isoform measured by western blotting is in part due to its variegated expression. The focal labeling of Ch-p53B and GFP-p53A was often adjacent to the nuclear envelope and in close proximity to the DAPI-bright chromocenter, similar to that observed after antiMyc labeling of the p53 isoform overexpression strains (Figures 3 and 4).

Some p53 complexes contain both p53A and p53B. Similar to mammalian p53, evidence suggests that the active Drosophila p53 transcription factor complex is a tetramer. ${ }^{36,51-54}$ We used the fluorescently tagged isoforms to examine whether some complexes contain both p53A and p53B. Larval brain and imaginal disc extracts were made 
a
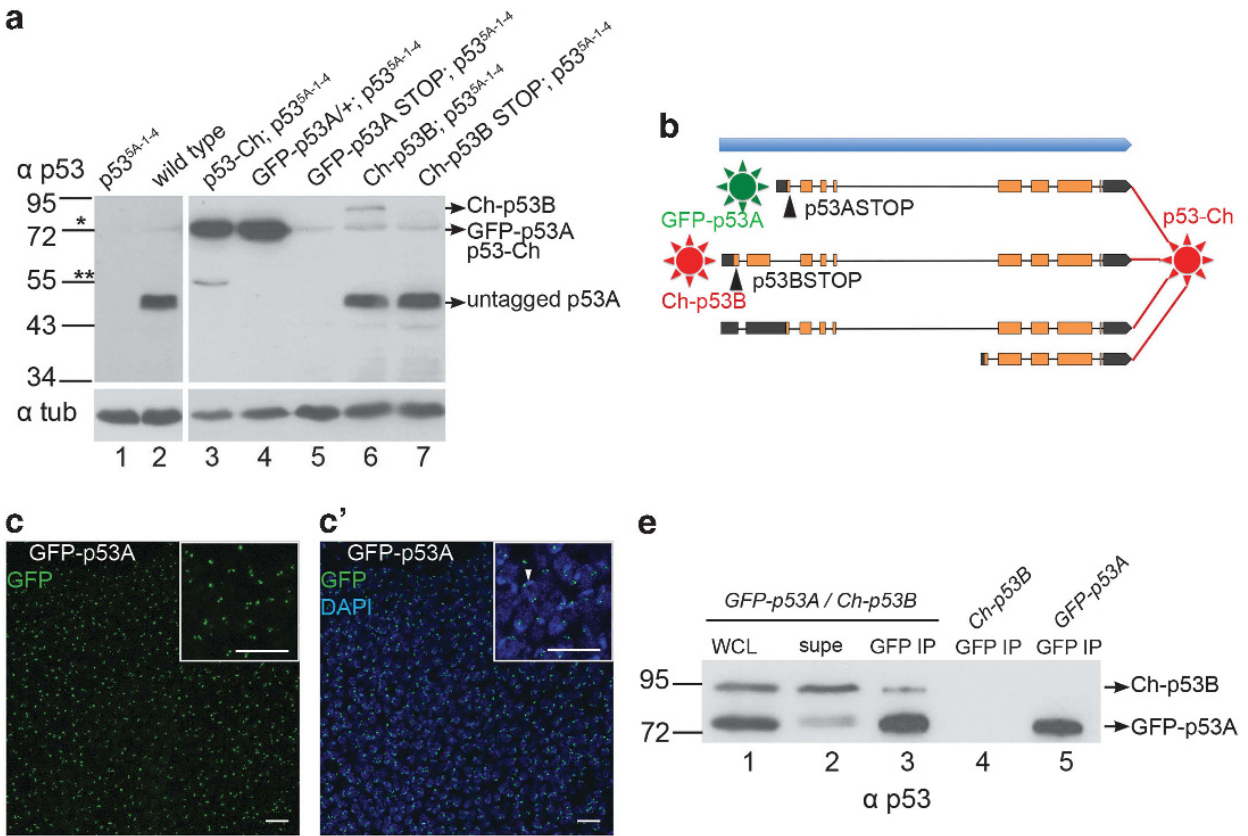

e
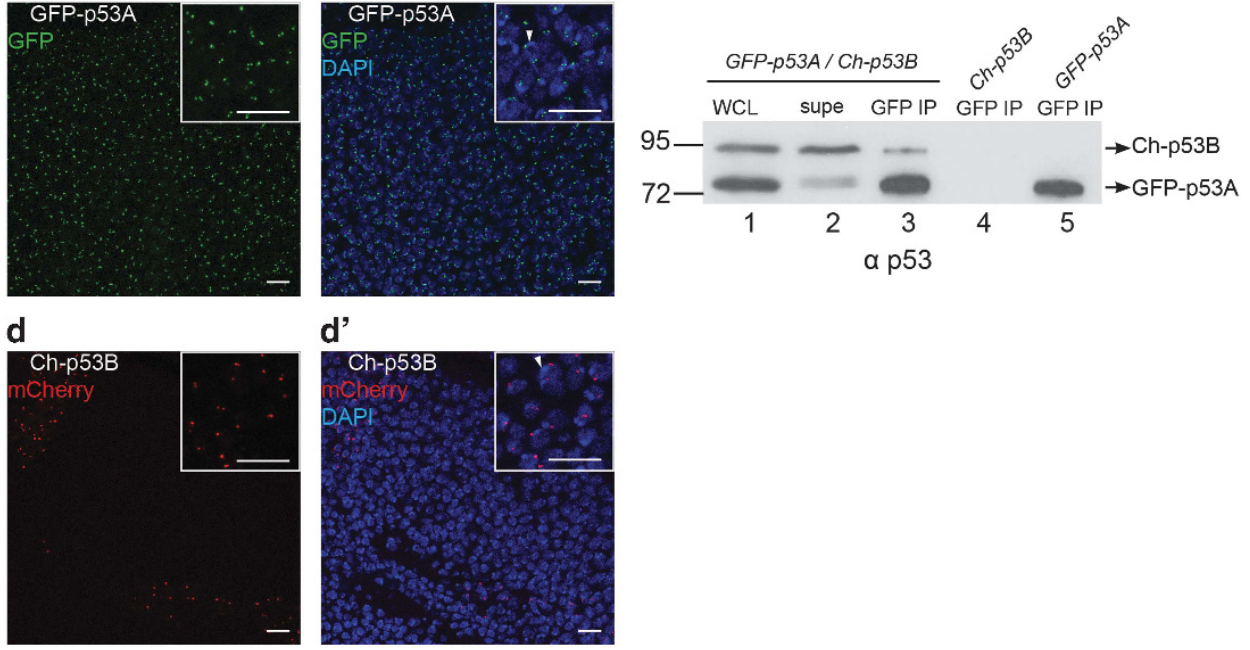

d'

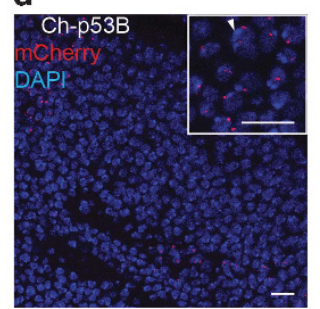

Figure 5 p53A is the most abundant isoform and associates with p53B. (a) Western blotting of extracts of larval brain and discs with anti-p53 antibodies. Lane 1: p53-null mutant. Lane 2: wild type. Lane 3-7: Epitope-tagged wild-type or stop codon mutant p53 expressed from the indicated transgenic BACs in a p53-null background. * indicates a faint non-specific band at $\sim 72 \mathrm{kD}$. ${ }^{*}$ indicates a degradation product of $\mathrm{p53}$-Ch. Loading control: Anti-alpha Tubulin. (b) A summary of the five BAC recombineered transgenes. Note that the isoform-specific mutant BACs still encode the other wild type, untagged isoforms (see Table 2). (c-d') GFP-p53A and Ch-p53B are concentrated in a nuclear compartment near the heterochromatic chromocenter. (c-c') GFP-p53A fluorescence (green) and DAPI labeling (blue) of third instar wing disc. (d-d') Ch-p53B mCherry fluorescence (red) and DAPI labeling (blue) of third instar wing disc. One chromocenter is indicated by an arrowhead in the insets of c' and d'. Scale bars are $10 \mu \mathrm{m}$ in panels and higher magnification insets. (e) GFP-p53A protein associates with Ch-p53B. GFP-nanobody IP from third instar B-D extract of the indicated genotypes followed by western blotting with anti-p53. Lane 1-3 from a GFP-p53A / Ch-p53B; $p 53^{5 A-1-4}$ strain. Lane 1: whole cell extract (WCL), Lane 2: supernatant after IP depletion (SUPE), Lane 3: GFP IP pellet. Lane 4: Control GFP-IP pellet from a Ch-p53B; $p 53^{3^{A A-1-4}}$ strain without GFP-p53A. Lane 5: Control GFP-IP from a GFP-p53A/+; $p 53^{5 A-1-4}$ without Ch-p53B

Table 2 BAC transgene protein coding and rescue of apoptosis

\begin{tabular}{|c|c|c|c|c|c|c|}
\hline \multirow[t]{2}{*}{ Predicted protein isoforms } & \multicolumn{6}{|c|}{ p53 BAC transgene } \\
\hline & p53 BAC ${ }^{a}$ & p53-Ch ${ }^{b}$ & GFP-p53A ${ }^{c}$ & GFP-p53A ${ }^{d}$ STOP & Ch-p53B ${ }^{c}$ & Ch-p53B ${ }^{d}$ STOP \\
\hline $\begin{array}{l}\text { A } \\
\text { B } \\
\text { D } \\
\text { E } \\
\text { Rescue? }\end{array}$ & $\begin{array}{c}A \\
B \\
D \\
E \\
\text { Yes }\end{array}$ & $\begin{array}{l}\text { A-Ch } \\
\text { B-Ch } \\
\text { D-Ch } \\
\text { E-Ch } \\
\text { Yes }\end{array}$ & $\begin{array}{c}\text { GFP-A } \\
\text { B } \\
D \\
\text { E } \\
\text { Yes }\end{array}$ & $\begin{array}{c}- \\
B \\
D \\
E \\
\text { No }\end{array}$ & $\begin{array}{c}\text { A } \\
\text { Ch-B } \\
D \\
E \\
\text { Yes }\end{array}$ & $\begin{array}{c}A \\
\bar{D} \\
E \\
\text { Yes }\end{array}$ \\
\hline
\end{tabular}

${ }^{a}$ Wild type BAC genomic clone. ${ }^{b} B A C$ with all wild-type protein isoforms tagged on the common C-terminus with fluorescent protein mCherry (Ch). ${ }^{c} B A C$ s with specific isoforms tagged on their unique N-terminus with mCherry (Ch-p53B) or Green Fluorescent Protein (GFP-p53A). ${ }^{d} B A C s$ with loss-of-function alleles of either p53A or p53B that have stop codons in their unique 5' exons

from strains containing both the GFP-p53A and $m C h-p 53 B$ BAC transgenes, GFP-p53A was immunoprecipitated (IP) with a highly efficient single chain nanobody against GFP, followed by western blotting with p53 antibodies. ${ }^{55}$ The results indicated that Ch-p53B co-IPs with GFP-p53A only from strains that express both fusions (Figure $5 \mathrm{e}$ ). These results suggest that some p53 complexes contain both p53A and p53B isoform subunits. 

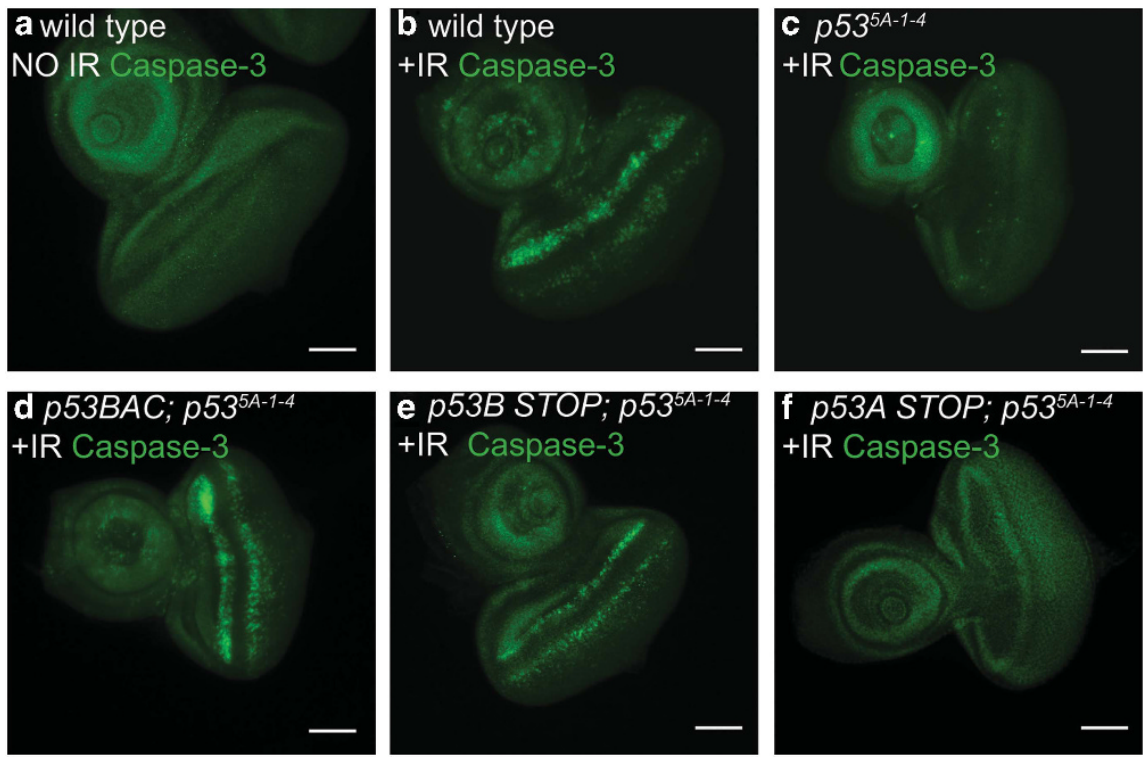

Figure 6 p53A, but not p53B, is required to mediate the apoptotic response to DNA damage. (a-f) Anti-cleaved Caspase-3 staining of third instar larval eye-antenna discs with (b-f) or without (a) IR. (a, b) Wild type. (c) p53-null mutant. (d-f) p53-null mutant with heterozygous wild type p53 BAC (d), Ch-p53BSTOP (e), or GFP-p53ASTOP (f) BAC transgenes. See Table 2. Scale bars are $100 \mu \mathrm{m}$

p53A is required for apoptosis and apoptotic gene expression in response to IR. The data indicated that p53A or p53B can induce apoptosis when overexpressed, with p53B clearly being the most potent inducer of apoptosis. It remained unknown, however, which p53 isoforms are required for the apoptotic response to DNA damage. To address this question, we determined whether the isoformspecific mutant BACs could rescue the apoptotic response of p53-null mutants. Within $4 \mathrm{~h}$ after irradiation, the imaginal discs of larvae homozygous for the null allele $p 53^{5 A-1-4}$ had very few cells labeled with anti-cleaved Caspase compared with wild type, consistent with previous reports that apoptosis at this early time point is largely dependent on p53 (Figures $6 \mathrm{a}-\mathrm{c}) .^{34,35,38,56}$ The wild-type p53 BAC or the $\mathrm{Ch}$ p53BSTOP (encodes p53A, C, and D/E) rescued the apoptotic response of the $p 53^{5 A-1-4}$ mutant (Figures $6 \mathrm{~d}$ and e,Table 2). In contrast, GFP-p53ASTOP (encodes p53B, C, and D/E) failed to rescue (Figure 6f, Table 2). These results suggest that $p 53 \mathrm{~A}$ is the isoform that is primarily required for the apoptotic response to DNA damage.

To examine which p53 isoforms are required to induce proapoptotic gene transcription after IR, we used a promoter reporter for the pro-apoptotic gene hid, (hid-GFP), which contains $2.2 \mathrm{~kb}$ of the hid promoter including a p53 response element (p53RE). ${ }^{42,57,58}$ Within $4 \mathrm{~h}$ after IR, hid-GFP expression was induced in larval imaginal discs of wild-type, but not p53 mutant, animals consistent with previous reports (Figures 7a and b). ${ }^{57,58}$ The Ch-p53BSTOP (encodes p53A, C, D/E) but not GFP-p53ASTOP (encodes p53B, C, D/E) rescued induction of hid-GFP expression in the $\mathrm{p} 53$ null strain, consistent with the results of the cleaved Caspase labeling that $\mathrm{p} 53 \mathrm{~A}$ is required for the early apoptotic response to radiation (Figures $7 c$ and $d$ ).

We next used RT-qPCR to examine the ability of different p53 isoforms to induce expression of the endogenous proapoptotic genes. Within $1.5 \mathrm{~h}$ of IR, the levels of reaper (rpr) and hid mRNA in imaginal discs increased about three- to fourfold in the p53 wild type but not p53 mutant animals, consistent with previous results (Figure 7e). ${ }^{42,59,60}$ The Chp53BSTOP; $p 53^{5 A-1-4}$ strain (encodes p53A, C, D/E) induced rprand hid transcription after IR to levels comparable with p53 wild-type strains, whereas the level of transcription in the GFPp53ASTOP; $p 53^{5 A-1-4}$ strain (encodes p53B, C, D/E) was indistinguishable from that in the $p 53^{5 A-1-4}$ null mutant (Figure 7e). Together, these data strongly suggest that it is the p53A isoform that is primarily required for the apoptotic response to DNA damage.

\section{Discussion}

We have investigated the apoptotic function of Drosophila p53 protein isoforms. Our results indicate that overexpression of any of the p53 isoforms perturbs development in multiple tissues. Overexpression of p53A or p53B both induced apoptosis, whereas the shorter isoforms p53D and p53E inhibited the apoptotic response to IR. Although p53B is a much stronger inducer of apoptosis when overexpressed, under physiological conditions, the p53A protein isoform is the most abundant and is the one required for the apoptotic response to ionizing irradiation. The overexpression and loss of function data together suggest that the potent p53B and shorter isoforms may have specialized functions that have yet to be defined. In a broader context, our results have provided a framework for understanding the function and evolution of isoforms in the ancient and complex p53 family.

The full-length p53B isoform was by far the most potent inducer of apoptosis when overexpressed, and in vertebrates, it is the full-length p53 isoform that is primarily responsible for the apoptotic response to genotoxic stress. These observations predicted that p53B would be required for apoptosis. Surprisingly, however, our loss-of-function data clearly indicate that it is the p53A isoform that is required for the activation 

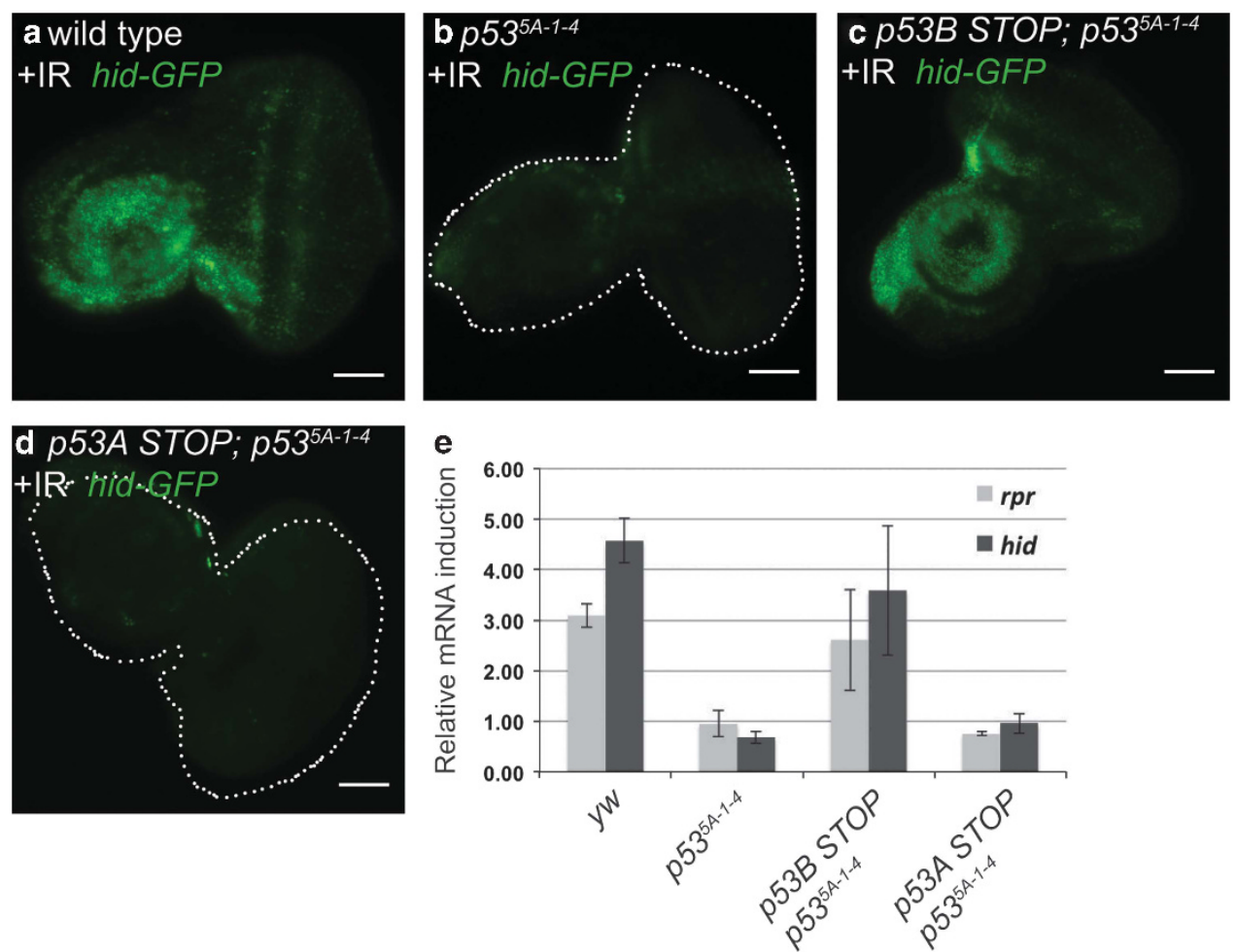

Figure 7 p53A, but not p53B, is required for the induction of pro-apoptotic gene expression in response to DNA damage. (a-d) Expression of the hid-GFP promoter reporter in third instar eye-antenna discs after IR. (a) Wild type. (b) p53-null mutant. (c) p53-null mutant with Ch-p53BSTOP. (d) p53-null mutant with GFP-p53ASTOP. Scale bars for a-d are $100 \mu \mathrm{m}$. (e) RT-qPCR quantification of endogenous rpr and hid mRNA expression in third instar larval brain and imaginal dics cells $1.5 \mathrm{~h}$ after IR. Expression levels were normalized to Act5C and the fold induction after IR is shown relative to before IR for each genotype. Error bars represent the range of data from two independent biological replicates

of transcription and apoptosis in response to IR. One explanation suggested by our data is that p53B is simply not expressed at high enough levels in most cells to mediate the apoptotic response. Indeed, keeping p53B in check may be crucial to restrain this potent inducer of apoptosis in the absence of stress. ModEncode RNA-Seq data and our previous analyses indicate that the higher levels of p53A protein relative to $\mathrm{p} 53 \mathrm{~B}$ and $\mathrm{p} 53 \mathrm{D} / \mathrm{E}$ is in part attributable to different levels of transcription of these isoforms from their dedicated promoters. ${ }^{39,42}$ It is possible, however, that in specific cell types p53B is expressed at higher levels and plays a more prominent role in stress response. The p53B isoform may also participate in other processes that Drosophila p53 has been implicated in, which include the culling of primordial germ cells, meiotic checkpoints, DNA repair, stem cell divisions, and tissue regeneration. ${ }^{41,60-69}$

Our results indicate that p53A and p53B localize to nuclear bodies and physically associate, an interaction that is likely direct through the conserved p53 oligomerization domain. Therefore, p53 tetramers may be heterogeneous and have different ratios of $\mathrm{p} 53 \mathrm{~A}$ and $\mathrm{p} 53 \mathrm{~B}$ subunits. Tetramers composed of all p53A subunits are likely the predominant form in most cells because p53A is the most highly expressed isoform. One possibility is that tetramers with different ratios of p53A and p53B have different strengths of transcriptional activation and perhaps collaborate with different co-factors to activate different target genes.
Although overexpression of the shortest isoforms, p53D and p53E, resulted in organismal lethality and perturbed eye development, there was no evidence that they induced apoptosis. On the contrary, the data support that these short isoforms are capable of inhibiting the apoptotic response to IR. This behavior is analogous to the ability of short isoforms of the p53, p63, and p73 genes in mammals and other organisms to inhibit apoptosis. ${ }^{2}$ It is important to note, however, that our current evidence is based on overexpression, and in which physiological context p53D or p53E may regulate apoptosis or other processes awaits further analysis.

Our data reveal striking similarities and differences between Drosophila and human p53 isoforms. While the longest Drosophila isoform p53B is most similar in size and structure to the full-length human p53 protein, the $110 \mathrm{AA}$ shorter p53A is structurally more similar to the human p53 $\triangle 40$ or p $53 \Delta 133$ isoforms which are truncated for the $\mathrm{N}$-terminal $40 \mathrm{AA}$ and 133 $A A$, respectively. ${ }^{15,16}$ The human $p 53 \Delta 40$ protein retains part of the N-terminal TAD and can promote transcription of p53 target genes, whereas p53 $\Delta 133$ lacks this domain and is primarily an inhibitor of the full-length p53 protein. ${ }^{16,70,71}$ In contrast, our data in Drosophila indicate that it is the $\mathrm{N}$-terminally truncated p53A that mediates the apoptotic response to IR. Sequence analysis suggests that the $\mathrm{N}$-terminus of $\mathrm{p} 53 \mathrm{~A}$ has a short TAD, and, therefore, is structurally similar to human p53 $\triangle 40$ in that it contains one of the two bipartite TADs encoded by full-length p53B (Figure 1a). Functionally, however, p53A is more like full- 
length human p53 in that it is the isoform that is primarily required for pro-apoptotic gene transcription and the apoptotic response to genotoxic stress in most tissues. The shorter p53D and p53E isoforms are functionally more analogous to p53 $\Delta 133$ in that they inhibit apoptosis. Thus, although the theme of multiple p53 isoforms has been conserved between humans and Drosophila, there is variation in the division of labor among isoforms in these two organisms. The different isoforms of the sole p53 gene in Drosophila may subsume the different functions of its vertebrate orthologs p53, p63, and p73 in stress response and development.

The p53 gene family is ancient with orthologs found in the genomes of phylogenetically diverse eukaryotes, including the single-celled Choanozoans, a paraphyletic group that is thought to have given rise to multicellular animals. ${ }^{14}$ The structure and function of the many p53, p63, and p73 isoforms has been intensively investigated in human, zebrafish, and mouse, but much less is known about protein isoform structure and function in other organisms. ${ }^{16}$ Drosophila p53 is more similar to human p53 in that it lacks the SAM protein-interaction domain found in the C-terminus of p63 and p73., $34-37$ Orthologs in many invertebrates, including ciliates, contain a SAM domain, suggesting that the p63 paralogs represent an ancestral form. ${ }^{7,36,37}$ Each of the orthologs in Molluscs and some Arachnids also encode multiple protein isoforms, suggesting that this property is an ancient attribute of the p53 gene family. ${ }^{14}$ Determining whether p53 family members in other organisms encode multiple protein isoforms, and how these isoforms regulate different processes, will provide further insight into the evolution and function of the p53 family.

\section{Materials and Methods}

Drosophila genetics. Fly strains were raised at $25^{\circ} \mathrm{C}$ prior to and during experimental procedures unless otherwise noted. Most fly strains were obtained from the Bloomington Drosophila Stock Center (BDSC, Bloomington, IN, USA). The hid-GFP fly strain was kindly provided by W. Du. A y $w^{67 c 23}$ strain was used as controls.

Construction of GAL4-inducible p53 transgenes. For construction of all the GAL4-inducible p53 isoforms, cDNAs were used as templates to generate $\mathrm{PCR}$ products spanning the start to stop codons of the open reading frame, tagged on the N-terminus with six copies of Myc, and cloned into the C31 transformation vector pUAST- $\mathrm{w}^{+}$-attB. All transgenes were transformed into the attP docking site at 65B2 (strain 24871) by Rainbow Transgenics (Camarillo, CA, USA).

BAC recombineering. The parental wild-type $\mathrm{BAC}$ was $\mathrm{CH} 322-178 \mathrm{C} 12$ from the P[acman] library and the derivative p53-Ch was tagged with mCherry on the C-terminus common to all the isoforms and has been described previously. ${ }^{42,50,72}$ The same parental BAC was used to create GFP-p53A and Ch-p53B which were tagged on their unique N-termini. For isoform-specific mutants, triple stop codons were introduced at the beginning of the open reading frames unique to GFP-p53A and Ch-p53B. All BACs were transformed into attP docking sites at cytogenetic position 22A3 (strain 24872).

Immunoblotting and nanobody IP. Protein extracts were prepared from hand-dissected tissues of mid-late third instar larvae by standard methods using RIPA buffer. ${ }^{73}$ Mouse anti- $\alpha$-tubulin was used as loading control. Western blotting was performed as previously described. ${ }^{74,75}$ Antibody dilutions are: mouse anti p53 (C11, Santa Cruz, Dallas, TX, USA) 1:500, mouse anti- $\alpha$-tubulin (clone DM1A, Sigma-Aldrich Corp., St. Louis, MO, USA) 1:5000, and anti-mouse secondary antibody, peroxidase labeled (KPL, Gaithersburg, MD, USA) at 1:5000.

For GFP nanobody IP, ${ }^{55}$ tissues were lysed in the following buffer: $25 \mathrm{~mm}$ Tris $\mathrm{pH}$ 7.5, $150 \mathrm{~mm} \mathrm{NaCl}, 5 \mathrm{~mm}$ EDTA, $1 \%$ Nonidet-P40,5\% glycerol. A total of $10-15 \mu$ l of Chromotek-GFP-Trap beads (Planegg-Martinsried, Germany) were added to the protein extracts and incubated for $2 \mathrm{~h}$ at $4^{\circ} \mathrm{C}$ and precipitated by brief centrifugation. SDS-PAGE sample buffer was added to the washed beads.

Immunohistochemistry. Mid-late third instar larvae and ovaries were dissected in either 1x PBS or Grace's solution, and fixed in 6\% formaldehyde as previously described, ${ }^{76,77}$ and immunolabeled using either anti-cleavedCaspase-3, 1:50 (Cell Signaling, Danvers, MA, USA) or anti-cleaved DCP-1 antibody, 1: 100 (Cell Signaling). Secondary antibodies were anti-rabbit Alexa 488 and anti-mouse Alexa 568 at 1:500 dilutions, and DNA was counterstained with DAPI. Wide-field micrographs in Figures 2, 5, 6 and 7 were taken on a Leica (Buffalo Grove, IL, USA) DMRA2 and analyzed using OpenLab (Improvision, Waltham, MA, USA) software. Confocal micrographs in Figures 3 and 4 were captured on a Leica SP5 confocal.

Gamma irradiation. For the experiments of Figure 4, females with hsp70: GAL4 and UAS:p53 transgenes were heat-treated at $37^{\circ} \mathrm{C}$ for $30 \mathrm{~min}$, and then irradiated with a total of $4000 \mathrm{rad}(40 \mathrm{~Gy})$ of gamma rays $2 \mathrm{~h}$ later. The ovaries of these females were dissected and labeled for DCP-1, $4 \mathrm{~h}$ after irradiation, corresponding to $6 \mathrm{~h}$ after heat induction. For Figure 7, larvae were irradiated and RNA prepared $1.5 \mathrm{~h}$ later, or labeled with anti-cleaved-Caspase-3 antibody $4 \mathrm{~h}$ later.

RNA isolation and real-time qPCR. Total RNA was isolated from handdissected tissues ( 20 larvae per sample) using TRIzol (15596-026, Invitrogen, Grand Island, NY, USA). RNA $(1 \mu \mathrm{g})$ from each sample was reverse-transcribed using the QuantiTect Reverse Transcription Kit (Qiagen, Valencia, CA, USA) according to the manufacturer's instructions. QPCR analysis was done on a Stratagene (Santa Clara, CA, USA) Mx3005P machine with SYBR Green Master Mix (600843; Agilent, Santa Clara, CA, USA). For mRNA quantification, Act 5C was used as a reference gene to calculate the relative expression (fold difference). PCR primer sequences are available upon request.

\section{Conflict of Interest}

The authors declare no conflict of interest.

Acknowledgements. We would like to thank R. Eisman, A. Tomlinson, S. Holtzman and T. Kaufman for their guidance on BAC recombineering and for embryo injections, and $\mathrm{H}$. Thirimanne for help with analysis of fluorescent transgenes. We also thank J. Powers of the Indiana Light Microscopy and Imaging Center (LMIC), the lowa Hybridoma Bank for antibodies, K. Matthews and K. Cook of the Bloomington Drosophila Stock Center, W. Du for fly strains, and Flybase for essential information. Thanks to members of the Calvi lab for helpful discussions. This work was supported by NIH R01 GM61290-11 and funding from the Walther Cancer Foundation to BRC.

1. Lane D, Levine A. p53 Research: the past thirty years and the next thirty years. Cold Spring Harb Perspect Biol 2010; 2: a000893.

2. Candi E, Agostini M, Melino G, Bernassola F. How the TP53 family proteins TP63 and TP73 contribute to tumorigenesis: regulators and effectors. Hum Mutat 2014; 35: 702-714.

3. Yonish-Rouach E, Resnitzky D, Lotem J, Sachs L, Kimchi A, Oren M. Wild-type p53 induces apoptosis of myeloid leukaemic cells that is inhibited by interleukin-6. Nature 1991; 352 : 345-347.

4. el-Deiry WS, Kern SE, Pietenpol JA, Kinzler KW, Vogelstein B. Definition of a consensus binding site for p53. Nat Genet 1992; 1: 45-49.

5. Lane DP. Cancer. p53, guardian of the genome. Nature 1992; 358: 15-16.

6. Melino G. p63 is a suppressor of tumorigenesis and metastasis interacting with mutant p53. Cell Death Differ 2011; 18: 1487-1499.

7. Dotsch V, Bernassola F, Coutandin D, Candi E, Melino G. p63 and p73, the ancestors of p53. Cold Spring Harb Perspect Biol 2010; 2: a004887.

8. Murray-Zmijewski F, Lane DP, Bourdon JC. p53/p63/p73 isoforms: an orchestra of isoforms to harmonise cell differentiation and response to stress. Cell Death Differ 2006; 13: 962-972.

9. Su X, Chakravarti D, Flores ER. p63 steps into the limelight: crucial roles in the suppression of tumorigenesis and metastasis. Nat Rev Cancer 2013; 13: 136-143.

10. Funk WD, Pak DT, Karas RH, Wright WE, Shay JW. A transcriptionally active DNA-binding site for human p53 protein complexes. Mol Cell Biol 1992; 12: 2866-2871.

11. Farmer G, Bargonetti J, Zhu H, Friedman P, Prywes R, Prives C. Wild-type p53 activates transcription in vitro. Nature 1992; 358: 83-86.

12. Vaseva AV, Moll UM. The mitochondrial p53 pathway. Biochim Biophys Acta 2009; 1787: $414-420$.

13. Aloni-Grinstein R, Shetzer $Y$, Kaufman T, Rotter V. p53: The barrier to cancer stem cell formation. FEBS Lett 2014; 588: 2580-2589. 
14. Rutkowski R, Hofmann K, Gartner A. Phylogeny and function of the invertebrate p53 superfamily. Cold Spring Harb Perspect Biol 2010; 2: a001131.

15. Bourdon JC, Fernandes K, Murray-Zmijewski F, Liu G, Diot A, Xirodimas DP et al. p53 isoforms can regulate p53 transcriptional activity. Gene Dev 2005; 19: 2122-2137.

16. Marcel V, Dichtel-Danjoy ML, Sagne C, Hafsi H, Ma D, Ortiz-Cuaran S et al. Biological functions of p53 isoforms through evolution: lessons from animal and cellular models. Cell Death Differ 2011; 18: 1815-1824.

17. Belyi VA, Ak P, Markert E, Wang H, Hu W, Puzio-Kuter $A$ et al. The origins and evolution of the p53 family of genes. Cold Spring Harbor Perspect Biol 2010; 2: a001198.

18. Mills AA. p53: link to the past, bridge to the future. Gene Dev 2005; 19: 2091-2099.

19. Courtois S, Verhaegh G, North S, Luciani MG, Lassus P, Hibner U et al. Delta N-p53, a natural isoform of p53 lacking the first transactivation domain, counteracts growth suppression by wild-type p53. Oncogene 2002; 21: 6722-6728.

20. Yin YL, Luciani MG, Fahraeus R. P53 stability and activity is regulated by Mdm2-mediated induction of alternative p53 translation products. Nat Cell Biol 2002; 4: 462-467.

21. Ghosh A, Stewart D, Matlashewski G. Regulation of human p53 activity and cell localization by alternative splicing. Mol Cell Biol 2004; 24: 7987-7997.

22. Brady CA, Jiang D, Mello SS, Johnson TM, Jarvis LA, Kozak MM et al. Distinct p53 transcriptional programs dictate acute DNA-damage responses and tumor suppression. Cell 2011; 145: 571-583.

23. Hamard PJ, Barthelery N, Hogstad B, Mungamuri SK, Tonnessen CA, Carvajal LA et al. The $C$ terminus of $p 53$ regulates gene expression by multiple mechanisms in a target- and tissuespecific manner in vivo. Genes Dev 2013; 27: 1868-1885.

24. Paris M, Rouleau M, Puceat M, Aberdam D. Regulation of skin aging and heart developmen by TAp63. Cell Death Differ 2012; 19: 186-193.

25. Mills AA, Zheng B, Wang XJ, Vogel H, Roop DR, Bradley A. p63 is a p53 homologue required for limb and epidermal morphogenesis. Nature 1999; 398: 708-713.

26. Suh EK, Yang A, Kettenbach A, Bamberger C, Michaelis AH, Zhu Z et al. p63 protects the female germ line during meiotic arrest. Nature 2006; 444: 624-628.

27. Su X, Chakravarti D, Cho MS, Liu L, Gi YJ, Lin YL et al. TAp63 suppresses metastasis through coordinate regulation of Dicer and miRNAs. Nature 2010; 467: 986-990.

28. Senoo M, Pinto F, Crum CP, McKeon F. p63 is essential for the proliferative potential of stem cells in stratified epithelia. Cell 2007; 129: 523-536.

29. Pignon JC, Grisanzio C, Geng Y, Song J, Shivdasani RA, Signoretti S. p63-expressing cells are the stem cells of developing prostate, bladder, and colorectal epithelia. Proc Natl Acad Sci USA 2013; 110: 8105-8110.

30. Romano RA, Smalley K, Magraw C, Serna VA, Kurita T, Raghavan S et al. DeltaNp63 knockout mice reveal its indispensable role as a master regulator of epithelial development and differentiation. Development 2012; 139: 772-782.

31. Yang A, Kaghad M, Wang Y, Gillett E, Fleming MD, Dotsch V et al. p63, a p53 homolog at 3q27-29, encodes multiple products with transactivating, death-inducing, and dominantnegative activities. Mol Cell 1998; 2: 305-316.

32. Tomasini R, Mak TW, Melino G. The impact of p53 and p73 on aneuploidy and cancer Trends Cell Biol 2008; 18: 244-252.

33. Inoue S, Tomasini R, Rufini A, Elia AJ, Agostini M, Amelio I et al. TAp73 is required for spermatogenesis and the maintenance of male fertility. Proc Natl Acad Sci USA 2014; 111 1843-1848.

34. Brodsky MH, Nordstrom W, Tsang G, Kwan E, Rubin GM, Abrams JM. Drosophila p53 binds a damage response element at the reaper locus. Cell 2000; 101: 103-113.

35. Ollmann M, Young LM, Di Como CJ, Karim F, Belvin M, Robertson S et al. Drosophila p53 is a structural and functional homolog of the tumor suppressor p53. Cell 2000; 101: 91-101.

36. Ou HD, Lohr F, Vogel V, Mantele W, Dotsch V. Structural evolution of C-terminal domains in the p53 family. EMBO J 2007; 26: 3463-3473.

37. Coutandin D, Ou HD, Lohr F, Dotsch V. Tracing the protectors path from the germ line to the genome. Proc Natl Acad Sci USA 2010; 107: 15318-15325.

38. Jin S, Martinek S, Joo WS, Wortman JR, Mirkovic N, Sali A et al. Identification and characterization of a p53 homologue in Drosophila melanogaster. Proc Natl Acad Sci USA 2000; 97: 7301-7306.

39. Boley N, Stoiber MH, Booth BW, Wan KH, Hoskins RA, Bickel PJ et al. Genome-guided transcript assembly by integrative analysis of RNA sequence data. N Biotechnol 2014; 32 341-346.

40. Marygold SJ, Leyland PC, Seal RL, Goodman JL, Thurmond J, Strelets VB et al. FlyBase: improvements to the bibliography. Nucleic Acids Res 2013; 41(Database issue) D751-D757.

41. Dichtel-Danjoy ML, Ma D, Dourlen P, Chatelain G, Napoletano F, Robin M et al. Drosophila p53 isoforms differentially regulate apoptosis and apoptosis-induced proliferation. Cell Death Differ 2013; 20: 108-116.

42. Zhang B, Mehrotra S, Ng WL, Calvi BR. Low levels of p53 protein and chromatin silencing of p53 target genes repress apoptosis in drosophila endocycling cells. PLoS Genet 2014; 10 : e1004581.

43. Sogame N, Kim M, Abrams JM. Drosophila p53 preserves genomic stability by regulating cell death. Proc Natl Acad Sci USA 2003; 100: 4696-4701.

44. Rong YS, Titen SW, Xie HB, Golic MM, Bastiani M, Bandyopadhyay P et al. Targeted mutagenesis by homologous recombination in D. melanogaster. Genes Dev 2002; 16 1568-1581.

45. Xie HB, Golic KG. Gene deletions by ends-in targeting in Drosophila melanogaster. Genetics 2004; 168: 1477-1489.
46. Ellis MC, O'Neill EM, Rubin GM. Expression of Drosophila glass protein and evidence for negative regulation of its activity in non-neuronal cells by another DNA-binding protein. Development 1993; 119: 855-865.

47. Fan Y, Lee TV, Xu D, Chen Z, Lamblin AF, Steller H et al. Dual roles of Drosophila p53 in cell death and cell differentiation. Cell Death Differ 2010; 17: 912-921.

48. Fraser AG, McCarthy NJ, Evan Gl. drlCE is an essential caspase required for apoptotic activity in Drosophila cells. EMBO J 1997; 16: 6192-6199.

49. Besse F, Pret AM. Apoptosis-mediated cell death within the ovarian polar cell lineage of Drosophila melanogaster. Development 2003; 130: 1017-1027.

50. Venken KJ, Carlson JW, Schulze KL, Pan H, He Y, Spokony R et al. Versatile P[acman] BAC libraries for transgenesis studies in Drosophila melanogaster. Nat Methods 2009; 6: 431-434.

51. Kraiss S, Quaiser A, Oren M, Montenarh M. Oligomerization of oncoprotein p53. J Virol 1988; 62: 4737-4744

52. Schmieg FI, Simmons DT. Characterization of the in vitro interaction between SV40 T antigen and p53: mapping the p53 binding site. Virology 1988; 164: 132-140.

53. Friedman PN, Chen X, Bargonetti J, Prives $C$. The p53 protein is an unusually shaped tetramer that binds directly to DNA. Proc Natl Acad Sci USA 1993; 90: 3319-3323.

54. Herzog G, Joerger AC, Shmueli MD, Fersht AR, Gazit E, Segal D. Evaluating Drosophila p53 as a model system for studying cancer mutations. J Biol Chem 2012; 287: 44330-44337.

55. Rothbauer U, Zolghadr K, Muyldermans S, Schepers A, Cardoso MC, Leonhardt H. A versatile nanotrap for biochemical and functional studies with fluorescent fusion proteins. $\mathrm{Mol}$ Cell Proteomics 2008; 7: 282-289.

56. Wichmann A, Jaklevic B, Su TT. lonizing radiation induces caspase-dependent but Chk2and p53-independent cell death in Drosophila melanogaster. Proc Natl Acad Sci USA 2006; 103: 9952-9957

57. Tanaka-Matakatsu M, Xu J, Cheng L, Du W. Regulation of apoptosis of rbf mutant cells during Drosophila development. Dev Biol 2009; 326: 347-356.

58. Wichmann A, Uyetake L, Su TT. E2F1 and E2F2 have opposite effects on radiation-induced p53-independent apoptosis in Drosophila. Dev Biol 2010; 346: 80-89.

59. Akdemir F, Christich A, Sogame N, Chapo J, Abrams JM. p53 directs focused genomic responses in Drosophila. Oncogene 2007; 26: 5184-5193.

60. Brodsky MH, Weinert BT, Tsang G, Rong YS, McGinnis NM, Golic KG et al. Drosophila melanogaster MNK/Chk2 and p53 regulate multiple DNA repair and apoptotic pathways following DNA damage. Mol Cell Biol 2004; 24: 1219-1231.

61. Wells BS, Yoshida E, Johnston LA. Compensatory proliferation in Drosophila imaginal discs requires Dronc-dependent p53 activity. Curr Biol 2006; 16: 1606-1615.

62. Abdu U, Brodsky M, Schupbach T. Activation of a meiotic checkpoint during Drosophila oogenesis regulates the translation of Gurken through Chk2/Mnk. Curr Biol 2002; 12: 1645-1651.

63. Bauer JH, Chang C, Bae G, Morris SN, Helfand SL. Dominant-negative Dmp53 extends life span through the dTOR pathway in D. melanogaster. Mech Ageing Dev 2010; 131: 193-201.

64. Lu WJ, Chapo J, Roig I, Abrams JM. Meiotic recombination provokes functional activation of the p53 regulatory network. Science 2010; 328: 1278-1281.

65. Ouyang Y, Song Y, Lu B. dp53 Restrains ectopic neural stem cell formation in the Drosophila brain in a non-apoptotic mechanism involving Archipelago and cyclin E. PLoS One 2011; 6 : e28098.

66. Waskar M, Landis GN, Shen J, Curtis C, Tozer K, Abdueva D et al. Drosophila melanogaster p53 has developmental stage-specific and sex-specific effects on adult life span indicative of sexual antagonistic pleiotropy. Aging 2009; 1: 903-936.

67. Wells BS, Johnston LA. Maintenance of imaginal disc plasticity and regenerative potential in Drosophila by p53. Dev Biol 2012; 361: 263-276.

68. Wylie A, Lu WJ, D'Brot A, Buszczak M, Abrams JM. p53 activity is selectively licensed in the Drosophila stem cell compartment. eLife 2014; 3: e01530.

69. Maezawa T, Arita K, Shigenobu S, Kobayashi S. Expression of the apoptosis inducer gene head involution defective in primordial germ cells of the Drosophila embryo requires eiger, p53, and loki function. Dev Growth Differ 2009; 51: 453-461.

70. Chen J, $\mathrm{Ng} \mathrm{SM}$, Chang C, Zhang Z, Bourdon JC, Lane DP et al. p53 isoform delta $113 \mathrm{p} 53$ is a p53 target gene that antagonizes p53 apoptotic activity via BclxL activation in zebrafish. Genes Dev 2009; 23: 278-290.

71. Chen J, Ruan H, Ng SM, Gao C, Soo HM, Wu W et al. Loss of function of def selectively upregulates Delta113p53 expression to arrest expansion growth of digestive organs in zebrafish. Genes Dev 2005; 19: 2900-2911.

72. Venken $\mathrm{KJ}, \mathrm{He}$ Y, Hoskins RA, Bellen HJ. P[acman]: a BAC transgenic platform for targeted insertion of large DNA fragments in D. melanogaster. Science 2006; 314: 1747-1751.

73. Harlow E, Lane D. Using Antibodies: A Laboratory Manual. Cold Spring Harbor Laboratory Press: Cold Spring Harbor, 1999.

74. Hassel C, Zhang B, Dixon M, Calvi BR. Induction of endocycles represses apoptosis independently of differentiation and predisposes cells to genome instability. Development 2014; 141: 112-123.

75. Maqbool SB, Mehrotra S, Kolpakas A, Durden C, Zhang B, Zhong H et al. Dampened activity of E2F1-DP and Myb-MuvB transcription factors in Drosophila endocycling cells. J Cell Sci 2010; 123(Pt 23): 4095-4106.

76. Schwed G, May N, Pechersky Y, Calvi BR. Drosophila minichromosome maintenance 6 is required for chorion gene amplification and genomic replication. Mol Biol Cell 2002; 13: $607-620$.

77. Mehrotra S, Maqbool SB, Kolpakas A, Murnen K, Calvi BR. Endocycling cells do not apoptose in response to DNA rereplication genotoxic stress. Genes Dev 2008; 22 3158-3171. 